\title{
Safety and Efficacy of Propranolol in Comparison With Combination of Fentanyl and Ketamine as Premedication in Cataract Surgery Under the Topical Anesthesia
}

\author{
Farhad Fazel ${ }^{1}$, Hamidhajigholam Saryazdi ${ }^{2}$, Leila Rezaei $^{3}$ \& Mohammad Mahboubi ${ }^{4,5}$ \\ ${ }^{1}$ Eye Research Center, Esfahan University of Medical Sciences, Esfahan, Iran \\ ${ }^{2}$ Esfahan University of Medical Sciences, Esfahan, Iran \\ ${ }^{3}$ Kermanshah University of Medical Sciences, Kermanshah, Iran \\ ${ }^{4}$ Abadan School of Medical Sciences, Abadan, Iran \\ ${ }^{5}$ Kermanshah University of Medical Sciences, Kermanshah, Iran \\ Correspondence: Hamidhajigholam Saryazdi, Associated professor of anesthesiology, Esfahan University of \\ Medical Sciences, Esfahan, Iran. Tel: 98-313-4452-0315. E-mail: leyla_rezaei60@yahoo.com
}

Received: January 5, 2015 Accepted: January 28, 2015 Online Published: March 30, 2015

doi:10.5539/gjhs.v7n6p88 URL: http://dx.doi.org/10.5539/gjhs.v7n6p88

\begin{abstract}
This study evaluated the safety and effects of propranolol as a premedication before cataract surgery and compared them with the usual combination doses of fentanyl and ketamine. Among all reffered patients to Feiz Hospital of Esfahan for cataract surgery, 122 patients between Mar to Sep 2010 were enrolled in this study and randomly allocated into one of the following equal groups: $40 \mathrm{mg}$ propranolol, 2 hours before surgery and combination of $15 \mathrm{mg}$ ketamine and $50 \mu \mathrm{g}$ fentanyl $1.5 \mathrm{~min}$ before surgery. The ability to control of hemodynamic instabilities caused by stress and to gain patients satisfaction was compared between two groups. Also, the efficacy of each premedication to control of hemodynamic changes during surgery were evaluated and compared. No significant differences were seen in the patients satisfaction and controlling of stress induced hemodynamic changes between two groups $(\mathrm{P}>0.05)$. However, patients in ketamine + fentanyl group showed more nausea and less pain during and after surgery. Moreover, no significant adverse effects were reported during and after the surgery. Our results demonstrated that propranolol can be used safely as a premedication in cataract surgery in the comparable efficacy to ketamine plus fentanyl premedication.
\end{abstract}

Keywords: propranolol, ketamine, fentanyl, cataract surgery, premedication

\section{Introduction}

Cataract is a clouding of the lens which can lead to visual disability. There are several causes for cataract formation include age (the most common cause), trauma, radiation, genetic, systemic diseases, drugs and etc. Age-related cataracts are responsible for about 51\% of world blindness (about 20 million people) in 2010 (Osei, 2011). Cataract extraction surgery is the most common ophthalmic surgery and commonly done under local anesthesia (Bakry, 2012). This is usually 'outpatient' and performed using topical anesthesia and about $90 \%$ of patients can achieve a corrected vision of 20/40 or better after surgery (Bollinger, 2008).

The principle goal of sedation for cataract surgery is to prepare the patient to stay calm during retrobulbar injection and surgery (Khezri, Oladi, \& Atlasbaf, 2013). Using of local anesthesia for ophthalmic operations provides clear immobile field with good patient and surgeon cooperation (Ayoglu, 2007). Therefore, most cataract surgeries in recent years are performed by phacoemulsification under topical anesthesia. Topical anesthesia protects patients from the possibility of globe perforations, optic nerve injury, and risk of respiratory arrest (Khezri \& Merate, 2013). Moreover, general anesthesia with opioids provides good perioperative analgesia in ocular surgeries but is associated with the risk of respiratory depression and postoperative emesis (Sethi, 2013).

Propranolol (Inderal) is a sympatholytic nonselective $\beta$-blocker which used to treat of hypertension, anxiety, and panic disorder (Kornischka, 2007). It has been reported that premedication with oral propranolol $10 \mathrm{mg}$ before hypotensive anesthesia with sodium nitroprusside is safe and effective to reduce reflex tachycardia and the 
amount of sodium nitroprusside used (Apipan \& Rummasak, 2010). Usually propranolol is used by paediatric cardiologists in children as young few weeks to treat tachydysrhythmias, idiopathic hypertrophic subaortic stenosis, paroxysmal hypoxaemic spells, long Q-T syndrome, and congenital heart failure at doses up to $8 \mathrm{mg} / \mathrm{kg} /$ day in divided doses (Reddy \& Cornish, 2012). Totally, cataract surgery by using local anesthesia and premedication with oral sedative drugs such as ketamine and fentanyl is highly recommended. However, the number of reports about using propranolol in oral route as cataract surgery premedication is scarce.

Therefore, in this present study, due to inexpensiveness and also availability of propranolol in comparison to other premedication agents, we investigated the effects of propranolol on stress induced hemodynamic instabilities, patients satisfaction and hemodynamic changes during surgery in patients that underwent cataract surgery under topical anesthesia and comparing with ketamine plus fentanyl premedication.

\section{Materials and Methods}

In a randomized controlled trial (RCT) with simple random sample selection, with assuming that satisfaction probability was $50 \%(\mathrm{p}=0.5)$ and $\alpha=0.05$, and $\mathrm{d}=0.18$, sample volume of 61 patients were calculated for each group. Our inclusion criteria were cooperation in clinical examination, first cataract surgery, having Persian language and filling conscious satisfaction form. Patients with body condition grades IV, V, and VI (based on ASA category), need to general anesthesia, myocardial infarction history (from 6 months ago), combined surgery procedure, history of bronchospasm, asthma and COPD, hypotension, cardiac block grade II and III, uncontrolled heart failure, concurrent use of sedative, hypnotic, opioid, beta blocker and ergotamine, and history of cerebrovascular accident (CVA) were excluded from our study.

Propranolol (Inderal) $40 \mathrm{mg}$ tablet 2 hours before cataract surgery in group I and combination of $15 \mathrm{mg}$ ketamine and $50 \mu \mathrm{g}$ fentanyl, $5 \mathrm{~min}$ before cataract surgery in groups II were administered. All patients were underwent small incision phacoemulsification surgery by one surgeon in Feiz Medical Center. Local anesthesia was performed with $0.5 \%$ lidocaine drip. Also, $1 \%$ mydriacyl eye drops contain the active ingredient tropicamide was used for inducing mydriasis. Each patient was monitored during the surgery and excluded from the study if needed any other interventions by surgeon or anesthesiologist.

The anthropomorphic data included age, occupation; education level and physical condition based on ASA category were obtained for each patient. Blood Pressure (BP) and Heart Rate (HR) were measured at three times: before, during and after surgery (in recovery). Systolic BP lower than $100 \mathrm{mmHg}$ was considered as hypotension, while, systolic or diastolic BP $\geq 140 / 90 \mathrm{mmHg}$ was considered as hypertension. Also, HR higher than 100 and lower than 60 were considered as tachycardia and bradycardia, respectively. Moreover, respiratory depression was defined as $\mathrm{O}_{2}$ saturation $\leq 90$. Measurement of patient satisfaction was performed in recovery by using Iowa Satisfaction Anesthesia Scale (ISAS) questionnaire with 11 options questions based on previous report. ISAS score more than 5.4 was considered as patient satisfaction (Fung, 2011).

Descriptive analysis was performed for reporting value in each parameter. Also, repeated measured ANOVA and mean rank comparison were performed for statistical analysis by using SPSS version 16.0. Independent sample $\mathrm{t}$ test for comparison between two treatment groups and Chi-square test for finding any correlation were used. P value under than 0.05 was considered as significant.

\section{Results}

Totally, 122 patients were included in this study at first, but seven patients from group ketamine+fentanyl and five patients from group propranolol were excluded due to lack of proper response in the questionnaire and therefore, 55 patients in each group were evaluated. These two groups were sex- and age-match $(\mathrm{p}>0.05)$. Frequency and percentage of patients in each group based on ASA category are presented in Table 1.

Table 1. The frequency and percentage of patients in both groups based on ASA category $(n=110)$

\begin{tabular}{llll}
\hline \multirow{2}{*}{ Groups } & \multicolumn{3}{c}{ ASA category } \\
\cline { 2 - 4 } & I & II & III \\
\hline Propranolol & $10(\% 18.2)$ & $21(\% 38.2)$ & $24(\% 43.6)$ \\
Ketamine + fentanyl & $17(\% 30.9)$ & $25(\% 45.5)$ & $13(\% 23.6)$ \\
\hline
\end{tabular}

Systolic, diastolic and arterial mean BP in each ASA category and each group in three different times of assessment are presented in Tables 2, 3 and 4, respectively. 
Table 2. Mean and SD of systolic blood pressure $(\mathrm{mmHg})$ in two groups based on different ASA category and in different time of assay

\begin{tabular}{llll}
\hline \multirow{2}{*}{ ASA category } & Time of assay & Group & \\
\cline { 3 - 4 } & & Propranolol & Ketamine + fentanyl \\
\hline \multirow{2}{*}{ I } & Before surgery & $127.00 \pm 16.19$ & $128.23 \pm 18.45$ \\
& During surgery & $124.00 \pm 16.96$ & $124.70 \pm 12.68$ \\
& After surgery & $122.50 \pm 12.96$ & $121.17 \pm 12.68$ \\
II & Before surgery & $123.25 \pm 12.16$ & $133.84 \pm 19.25$ \\
& During surgery & $124.50 \pm 9.58$ & $134.42 \pm 17.22$ \\
& After surgery & $121.75 \pm 9.49$ & $120.96 \pm 11.13$ \\
III & Before surgery & $127.29 \pm 15.53$ & $137.30 \pm 19.64$ \\
& During surgery & $131.45 \pm 16.51$ & $133.84 \pm 12.60$ \\
\hline
\end{tabular}

Table 3. Mean and SD of diastolic blood pressure $(\mathrm{mmHg})$ in two groups based on different ASA category and in different time of assay

\begin{tabular}{llll}
\hline \multirow{2}{*}{ ASA category } & Time of assay & \multicolumn{2}{l}{ Group } \\
\cline { 3 - 4 } & & Propranolol & Ketamine + fentanyl \\
\hline \multirow{2}{*}{ I } & Before surgery & $76.00 \pm 5.16$ & $77.50 \pm 5.87$ \\
& During surgery & $72.00 \pm 9.18$ & $74.41 \pm 8.63$ \\
& After surgery & $72.00 \pm 7.52$ & $71.76 \pm 7.89$ \\
II & Before surgery & $74.25 \pm 6.12$ & $77.88 \pm 8.38$ \\
& During surgery & $74.00 \pm 5.98$ & $77.88 \pm 9.29$ \\
& After surgery & $72.75 \pm 4.72$ & $73.26 \pm 7.20$ \\
III & Before surgery & $77.50 \pm 9.44$ & $76.92 \pm 10.31$ \\
& During surgery & $78.75 \pm 10.45$ & $77.30 \pm 9.70$ \\
& After surgery & $76.04 \pm 9.55$ & $77.69 \pm 8.06$ \\
\hline
\end{tabular}

Table 4. Mean and SD of arterial mean blood pressure $(\mathrm{mmHg})$ in two groups based on different ASA category and in different time of assay

\begin{tabular}{llll}
\hline \multirow{2}{*}{ ASA category } & Time of assay & Group & \\
\cline { 3 - 4 } & & Propranolol & Ketamine + fentanyl \\
\hline \multirow{2}{*}{ I } & Before surgery & $93.00 \pm 8.19$ & $94.11 \pm 9.46$ \\
& During surgery & $89.33 \pm 10.31$ & $91.17 \pm 8.91$ \\
& After surgery & $88.83 \pm 7.97$ & $88.23 \pm 8.50$ \\
II & Before surgery & $90.58 \pm 7.32$ & $96.53 \pm 11.04$ \\
& During surgery & $90.83 \pm 6.17$ & $96.73 \pm 10.35$ \\
& After surgery & $89.08 \pm 5.14$ & $89.16 \pm 7.38$ \\
III & Before surgery & $94.09 \pm 11.03$ & $97.05 \pm 12.65$ \\
& During surgery & $96.31 \pm 11.37$ & $96.15 \pm 9.01$ \\
& After surgery & $92.56 \pm 10.04$ & $93.84 \pm 7.43$ \\
\hline
\end{tabular}

Comparison of mean and SD of systolic, diastolic and arterial mean BP and also HR in different groups at 
different time of assessment without considering ASA category are showed in Figure 1.
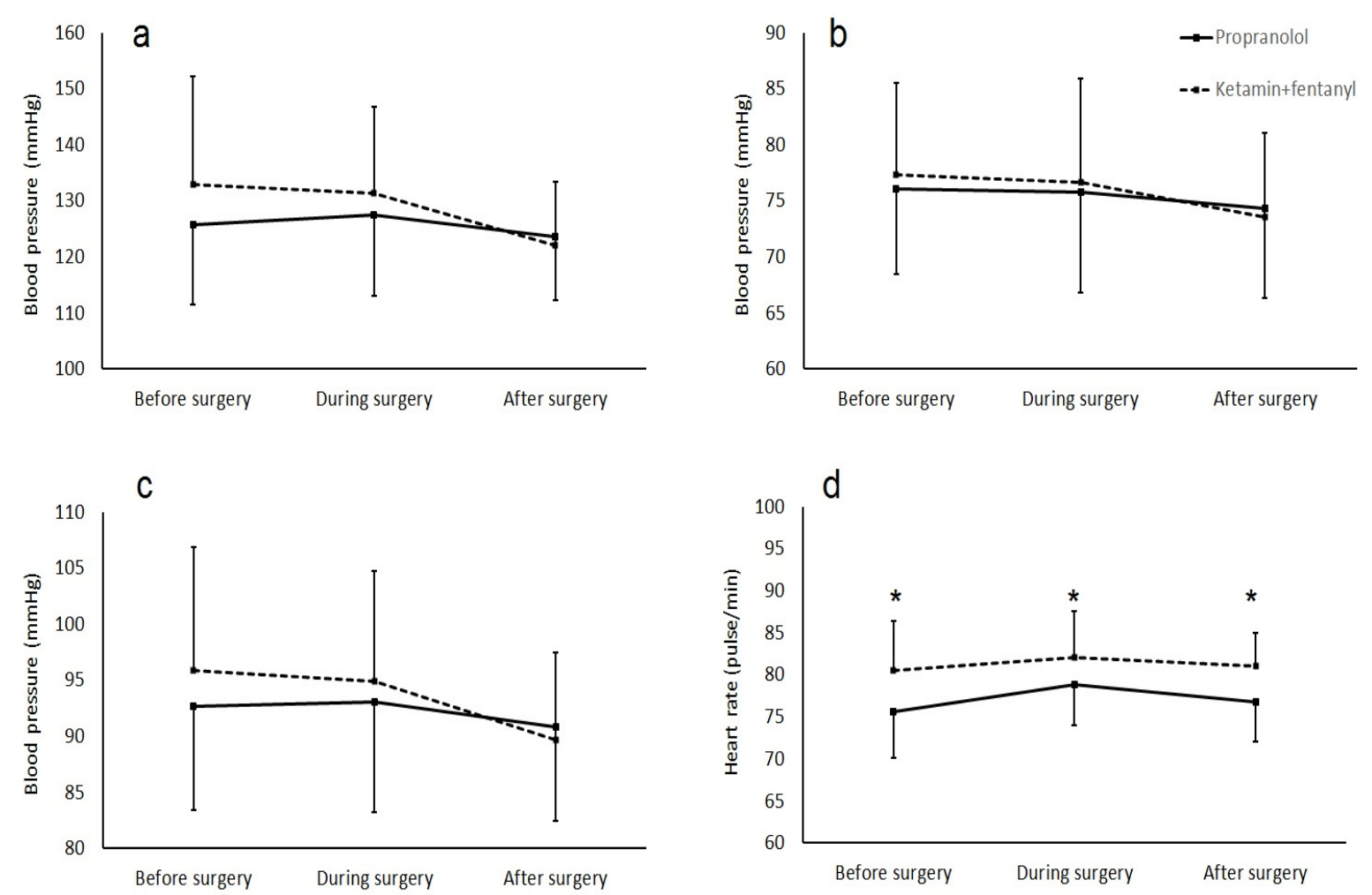

Figure 1. Comparison of mean and SD of systolic (a), diastolic (b), arterial mean (c) blood pressure and heart rate (d) in different groups at different time of assessment. Significant difference between two groups was indicated by asterisk. $(\mathrm{P}=0.001)$

There were no significant differences between propranolol and ketamine + fentanyl groups in percentage of $\mathrm{O}_{2}$ saturation before $(97.63 \pm 1.09$ vs. $97.54 \pm 1.15 \%$, respectively, $\mathrm{p}=0.67)$ and during surgery $(98.34 \pm 0.79$ vs. $98.10 \pm 1.13 \%$, respectively, $\mathrm{p}=0.20$ ). Comparison of frequency and percentage of incooperation, pain feeling and nausea during the surgery and also patient's satisfaction after surgery between two groups are presented in Table 5. Comparison of ISAS score between propranolol and ketamine+fentanyl groups showed no significant difference ( $4.48 \pm 0.79$ vs. $4.47 \pm 0.74 \%$, respectively, $\mathrm{p}=0.62)$.

Table 5. Frequency and percentage of incooperation, pain feeling and nausea during the surgery and patient's satisfaction after surgery in two groups

\begin{tabular}{llll}
\hline Parameters & Groups & Frequency (percentage) & P value \\
\hline Incooperation & Propranolol & $4(7.3)$ & 0.72 \\
\multirow{2}{*}{ Pain feeling } & Ketamine + fentanyl & $5(9.1)$ & 0.29 \\
& Propranolol & $19(34.5)$ & $<0.001$ \\
Nausea & Ketamine + fentanyl & $13(23.6)$ & $5(9.1)$ \\
\multirow{2}{*}{ Patient's satisfaction } & Propranolol & $23(41.8)$ & 0.29 \\
& Ketamine + fentanyl & $49(81.9)$ & $52(94.5)$ \\
\hline
\end{tabular}


In both groups, all surgical procedures were continued and finished without any problems. Also, there was no significant difference between propranolol and ketamine+fentanyl groups in duration of surgery $(21.27 \pm 3.75 \mathrm{vs}$. $21.81 \pm 3.64 \mathrm{~min}$, respectively, $\mathrm{p}=0.44$ ).

\section{Discussion}

This study compared the BP and HR changes, duration of surgery, complication and patient's satisfaction in response to using propranolol with routine ketamine+fentanyl as premedication for cataract surgery. Our results demonstrated that HR and probability of nausea in using ketamine+fentanyl were significantly higher than propranolol as premedication. Also, premedication with propranolol can induced reasonable and comparable satisfaction and painlessness against ketamine+fentanyl and be without any complications. Therefore, propranolol can be used instead of ketamine+fentanyl due to inexpensiveness and producing favorable results.

The number of reports about using of propranolol as premedication for cataract surgery is scarce and most use of propranolol in the field of eye diseases is related to treatment of hemangioma (Xue \& Hildebrand, 2012; Missoi, 2011; Al-Dhaybi, 2011). However, a recent study was performed which discussed the pharmacokinetics and local safety profile of propranolol eye drops in animal model rabbits. They demonstrated that propranolol eye drops are able to ensure high retinal and low plasma concentrations of propranolol (Padrini, 2014). Also, the safety and efficacy of oral propranolol administration in preterm newborns affected by an early phase of retinopathy of prematurity (ROP) were evaluated and demonstrated that the administration of oral propranolol is effective in counteracting the progression of ROP but that safety is a concern (Filippi, 2013).

Anxiety before surgery can stimulate catecholamine secretion and induce hemodynamic inconstancy. Using of sedative drugs as premedication can overcome this anxiety and prepare patient for surgery. However, adjuvant intravenous anesthetic agents such as opioids, benzodiazepines, and other hypnotic sedative agents used to decrease pain and alleviate anxiety are associated with increases in medical events (Katz, 2001). The most important complications of these drugs include hypotension, bradycardia, respiratory and CNS depression, decline in arterial $\mathrm{O} 2$ saturation and also incooperation of patients (Ahmad, 2008). On the other hand, hypertension is the most common, and approximately half of the cataract patients have hypertension. In addition, patients with HR perform cataract surgery approximately twice more often than other patients. Also, BP tends to rise during cataract surgery (Çakmak, 2014). Propranolol as a beta adrenergic blocker can overcome most of hemodynamic features of anxiety and it has attracted the attention of physicians for using as premedication before surgery. Elman et al. reported that propranolol, $40 \mathrm{mg}$, administered 1 hour prior to surgery, significantly decreased anxiety in both surgeon and patients (Elman, 1998). Also, in another study, Gopal and his colleagues reported that propranolol $(40 \mathrm{mg})$ given 2 hours prior to cataract surgery under local anesthesia reduces perioperative rise in HR and BP. Also, they reported that relative to controls, cases showed lower mean pulse rate and mean systolic BP at all-time intervals. They concluded propranolol effectively reduces anxiety before and during the surgery (Gopal, 2005). Our results are in agreement with all other previous reports and demonstrated the beneficial effects of propranolol as premedication for cataract surgery.

\section{Conclusion}

In conclusion our results demonstrated that propranolol can be used as premedication for cataract surgery without any complication and also provide similar and sometimes more efficacy than routine ketamine plus fentanyl premedication. However, further studies in different age group and also different eye disease are needed to confirm the findings of this study.

\section{Acknowledgments}

This study was entirely financed by Esfahan University of Medical Sciences.

\section{Authors Contribution}

This work was carried out in collaboration among all authors.

\section{Conflict of Interest}

The authors declared no potential conflicts of interests with respect to the authorship and/or publication of this article.

\section{References}

Ahmad, S. (2006). Sedation techniques in ophthalmic anesthesia. Ophthalmology clinics of North America, 19(2), 193-202.

Al Dhaybi, R., Superstein, R., Milet, A., Powell, J., Dubois, J., McCuaig, C., ... Ospina, L. H. (2011). Treatment 
of periocular infantile hemangiomas with propranolol: case series of 18 children. Ophthalmology, 118(6), 1184-1188. http://dx.doi.org/10.1016/j.ophtha.2010.10.031

Apipan, B., \& Rummasak, D. (2010). Efficacy and safety of oral propranolol premedication to reduce reflex tachycardia during hypotensive anesthesia with sodium nitroprusside in orthognathic surgery: A double-blind randomized clinical trial. Journal of Oral and Maxillofacial Surgery, 68(1), 120-124. http://dx.doi.org/10.1016/j.joms.2009.07.065

Ayoglu, H., Altunkaya, H., Ozer, Y., Yapakci, O., Ozkocak, I., Oz, O., ... Ugurbas, S. H. (2007). Dexmedetomidine sedation during cataract surgery under regional anaesthesia. British journal of anaesthesia, 99(3), 448-448. http://dx.doi.org/10.1093/bja/aem226

Bakry, A. E. A. E., \& Marey, H. (2012). The effect of gabapentin premedication on pain and anxiety during cataract surgery under peribulbar block. Egyptian Journal of Anaesthesia, 28(1), 43-47.3.3. http://dx.doi.org/10.1016/j.egja.2011.10.001

Bollinger, K. E., \& Langston, R. H. (2008). What can patients expect from cataract surgery?. Cleveland Clinic journal of medicine, 75(3), 193-200. http://dx.doi.org/10.3949/ccjm.75.3.193

Çakmak, H., Kocatürk, T., Dündar, S. O., Kaan, N., Özbağçivan, M., \& Erkan, E. (2014). The effects of diazepam on blood pressure levels in cataract surgery. Saudi medical journal, 35(7), 669-673.

Elman, M. J., Sugar, J., Fiscella, R., Deutsch, T. A., Noth, J., Nyberg, M., ... \& Anderson, R. J. (1998). The effect of propranolol versus placebo on resident surgical performance. Transactions of the American Ophthalmological Society, 96, 283.

Filippi, L., Cavallaro, G., Bagnoli, P., Dal Monte, M., Fiorini, P., Donzelli, G., ... \& Mosca, F. (2013). Oral propranolol for retinopathy of prematurity: risks, safety concerns, and perspectives. The Journal of pediatrics, 163(6), 1570-1577. http://dx.doi.org/10.1016/j.jpeds.2013.07.049

Fung, D., Cohen, M., Stewart, S., \& Davies, A. (2005). Can the Iowa Satisfaction with Anesthesia Scale be used to measure patient satisfaction with cataract care under topical local anesthesia and monitored sedation at a community hospital?. Anesthesia \& Analgesia, 100(6), 1637-1643. http://dx.doi.org/10.1213/01.ANE.0000154203.00434.23

Gopal, L., Pathengay, A., Bhaskaran, S., Sailender, G. V., Misra, K. P., \& Badrinath, S. S. (2005). Study of propranalol as a premedication in cataract surgery a pilot study. Annals of Ophthalmology, 37(3), 207-210. http://dx.doi.org/10.1385/AO:37:3:207

Katz, J., Feldman, M. A., Bass, E. B., Lubomski, L. H., Tielsch, J. M., Petty, B. G., ... \& Schein, O. D. (2001). Adverse intraoperative medical events and their association with anesthesia management strategies in cataract surgery. Ophthalmology, 108(10), 1721-1726. http://dx.doi.org/10.1016/S0161-6420(01)00704-7

Khezri, M. B., \& Merate, H. (2013). The effects of melatonin on anxiety and pain scores of patients, intraocular pressure, and operating conditions during cataract surgery under topical anesthesia. Indian journal of ophthalmology, 61(7), 319. http://dx.doi.org/10.4103/0301-4738.99637

Khezri, M. B., Oladi, M. R., \& Atlasbaf, A. (2013). Effect of melatonin and gabapentin on anxiety and pain associated with retrobulbar eye block for cataract surgery: A randomized double-blind study. Indian journal of pharmacology, 45(6), 581. http://dx.doi.org/10.4103/0253-7613.121368

Kornischka, J., Cordes, J., \& Agelink, M. W. (2007). [40 years beta-adrenoceptor blockers in psychiatry]. Fortschritte der Neurologie-Psychiatrie, 75(4), 199-210. http://dx.doi.org/10.1055/s-2006-944295

Missoi, T. G., Lueder, G. T., Gilbertson, K., \& Bayliss, S. J. (2011). Oral propranolol for treatment of periocular $\begin{array}{llll}\text { infantile hemangiomas. Archives of ophthalmology, } & \text { 129(7), }\end{array}$ http://dx.doi.org/10.1001/archophthalmol.2011.40

Osei, P. D., \& Nwasike, J. N. (2011). Commonwealth Health Ministers' Update 2011. Commonwealth Secretariat.

Padrini, L., Isacchi, B., Bilia, A. R., Pini, A., Lanzi, C., Masini, E., ... Filippi, L. (2014). Pharmacokinetics and local safety profile of propranolol eye drops in rabbits. Pediatric research. http://dx.doi.org/10.1038/pr.2014.108

Reddy, A. R., \& Cornish, K. S. (2012). Response to Dr Norris and Dr McCulloch. Eye, 26(9), 1276. http://dx.doi.org/10.1038/eye.2012.117 
Sethi, S., Ghai, B., Sen, I., Ram, J., \& Wig, J. (2013). Efficacy of subtenon block in infants-a comparison with intravenous fentanyl for perioperative analgesia in infantile cataract surgery. Pediatric Anesthesia, 23(11), 1015-1020. http://dx.doi.org/10.1111/pan.12227

Xue, K., \& Hildebrand, G. D. (2012). Topical timolol maleate $0.5 \%$ for infantile capillary haemangioma of the eyelid. British Journal of Ophthalmology, bjophthalmol-2012.

\section{Copyrights}

Copyright for this article is retained by the author(s), with first publication rights granted to the journal.

This is an open-access article distributed under the terms and conditions of the Creative Commons Attribution license (http://creativecommons.org/licenses/by/3.0/). 